\title{
MAPK inhibitors enhance cell death in pyrogallol-treated human pulmonary fibroblast cells via increasing $\mathrm{O}_{2}{ }^{-0}$ levels
}

\author{
BO RAM HAN and WOO HYUN PARK
}

\author{
Department of Physiology, Medical School, Research Institute for Endocrine Sciences, \\ Chonbuk National University, Jeonju, Jeollabuk 54907, Republic of Korea
}

Received January 27, 2016; Accepted March 21, 2017

DOI: $10.3892 / \mathrm{ol} .2017 .6185$

\begin{abstract}
Pyrogallol (PG) induces apoptosis in lung cancer cells via the overproduction of $\mathrm{O}_{2}{ }^{--}$and affects mitogen-activated protein kinases (MAPKs) in these cells. The aim of the present study was to elucidate the effect of PG and/or MAPK inhibitors on human pulmonary fibroblast (HPF) cell viability in relation to reactive oxygen species (ROS) and glutathione (GSH). Treatment with 50 or $100 \mu \mathrm{M}$ PG inhibited the viability of HPF cells, and induced cell death and the loss of mitochondrial membrane potential (MMP; $\Delta \Psi_{\mathrm{m}}$ ). In particular, treatment with $100 \mu \mathrm{M}$ PG induced cell death via apoptosis as well as necrosis in HPF cells. PG increased mitochondrial $\mathrm{O}_{2}{ }^{--}$levels and the number of GSH-depleted HPF cells. All the MAPK (mitogen-activated protein kinase kinase, c-Jun N-terminal kinase and p38) inhibitors enhanced the inhibition of cell viability, cell death and MMP $\left(\Delta \Psi_{\mathrm{m}}\right)$ loss in $100 \mu \mathrm{M}$ PG-treated HPF cells. All the inhibitors increased the $\mathrm{O}_{2}^{-}{ }^{-}$levels in $100 \mu \mathrm{M}$ PG-treated HPF cells, but none of the inhibitors significantly altered the PG-induced GSH depletion. In conclusion, PG treatment induced cell death via apoptosis and necrosis in HPF cells. Treatment with MAPK inhibitors slightly enhanced cell death in PG-treated HPF cells. HPF cell death induced by PG and/or MAPK inhibitors was at least partially associated with changes in $\mathrm{O}_{2}{ }^{-}$levels and GSH content. The present data provided useful information to
\end{abstract}

Correspondence to: Professor Woo Hyun Park, Department of Physiology, Medical School, Research Institute for Endocrine Sciences, Chonbuk National University, 20 Geonji Street, Deokjin, Jeonju, Jeollabuk 54907, Republic of Korea

E-mail: parkwh71@chonbuk.ac.kr

Abbreviations: HPF, human pulmonary fibroblast; PG, pyrogallol; ROS, reactive oxygen species; MMP $\left(\Delta \Psi_{\mathrm{m}}\right)$, mitochondrial membrane potential; GSH, glutathione; MAPK, mitogen-activated protein kinase; MEK, mitogen-activated protein kinase kinase; ERK, extracellular signal-regulated kinase; JNK, c-Jun N-terminal kinase; LDH, lactate dehydrogenase; $\mathrm{H}_{2}$ DCFDA, 2',7'-dichlorodihydrofluorescein diacetate; DHE, dihydroethidium; CMF, 5-chloromethylfluorescein diacetate

Key words: human pulmonary fibroblast, pyrogallol, cell death, mitogen-activated protein kinase inhibitor, reactive oxygen species understand PG-induced normal lung cell death in association with MAPK signaling pathways and ROS levels.

\section{Introduction}

Pyrogallol (PG; benzene-1,2,3-triol) is a polyphenol compound that is commonly distributed in hard wood plants, and it has anti-fungal and anti-psoriatic properties (1). PG is a reductant that is able to generate free radicals, in particular superoxide anions $\left(\mathrm{O}_{2}{ }^{-}\right)$, so has frequently been used as a photographic developing agent and in the hair dying industry (1). Despite the useful effects of PG, its toxicity remains a concern for the individuals exposed to it. Multiple studies have been performed to elucidate the toxicological and pharmacological effects of PG (2-4). However, the molecular mechanisms underlying the cellular effects of PG remain only partially clarified. For example, $\mathrm{PG}$ induces $\mathrm{O}_{2}{ }^{-}$-mediated death of various types of cell, including human lymphoma cells (5), human glioma cells (6), gastric cancer cells (7) and Calu-6 lung cancer cells $(8,9)$. In addition, PG triggers mutagenesis, carcinogenesis and impairs the immune system (1).

$\mathrm{O}_{2}{ }^{--}$, hydrogen peroxide $\left(\mathrm{H}_{2} \mathrm{O}_{2}\right)$ and hydroxyl radicals $\left({ }^{\circ} \mathrm{OH}\right)$ are reactive oxygen species (ROS). These are involved in various cellular events, including gene expression, cell signaling, differentiation, cell growth and cell death. ROS are primarily generated during mitochondrial respiration and are specifically made by various oxidases (10). Superoxide dismutases convert $\mathrm{O}_{2}{ }^{--}$to $\mathrm{H}_{2} \mathrm{O}_{2}$ (11). Further metabolism yields $\mathrm{O}_{2}$ and $\mathrm{H}_{2} \mathrm{O}$ via catalase or glutathione (GSH) peroxidase (12). Oxidative stress resulting from either overproduction of ROS or loss of antioxidant enzymes may initiate cellular signaling events that lead to cell death, depending on cell type. There is evidence to suggest that ROS not only affect extracellular signal regulated kinase 1/2 (ERK1/2) and mitogen-activated protein kinase kinase (MEK) activation (13) but also activate c-Jun $\mathrm{N}$-terminal kinase/stress-activated protein kinase (JNK/SAPK) and p38 (14,15). ERK1/2, JNK/SAPK and p38 are mitogen-activated protein kinases (MAPKs), which are components of signaling pathways associated with cell proliferation, differentiation and cell death (16). Each kinase has different upstream activators and specific downstream substrates (17). In general, MEK-ERK signaling is pro-survival rather than pro-apoptotic (18). JNK and p38 signaling pathways are associated with cell death $(14,15,19)$. 
The human lung is a structurally complex organ system (20). Fibroblast cells, which are primarily derived from the primitive mesenchyme, synthesize extracellular matrix components including collagen to maintain the structural and functional integrity of the lung connective tissues. Human pulmonary fibroblast (HPF) cells are involved in lung inflammation, fibrosis and cancer (21). Cultured normal human cells are frequently used in mechanistic studies of oxidative stress, being invaluable biological models $(22,23)$. PG inhibits Calu-6 and A549 lung cancer cell growth via apoptosis $(8,24,25)$ and depletion of GSH $(24,26)$. In addition, MEK inhibitors, but not JNK or p38 inhibitors, have been demonstrated to slightly attenuate inhibition of cell growth, cell death and GSH depletion in PG-treated Calu-6 cells (27). The present study investigated the effect of MAPK inhibitors on PG-treated HPF cell death, in relation to ROS and GSH levels.

\section{Materials and methods}

Cell culture. HPF cells were obtained from PromoCell GmbH (Heidelberg, Germany) and were cultured in RPMI-1640 medium (GE Healthcare Life Sciences, Logan, UT, USA) supplemented with $10 \%$ fetal bovine serum (Sigma-Aldrich; Merck KGaA, Darmstadt, Germany) and $1 \%$ penicillin-streptomycin (Gibco; Thermo Fisher Scientific, Inc., Waltham, MA, USA) in humidified incubator containing $5 \% \mathrm{CO}_{2}$ at $37^{\circ} \mathrm{C}$. HPF cells were used for experiments between passages four and eight.

Reagents. PG (Sigma-Aldrich; Merck KGaA) was dissolved in water at $100 \mathrm{mM}$ as a stock solution. The MEK inhibitor (PD98059), JNK inhibitor (SP600125) and p38 inhibitor (SB203580) were obtained from Calbiochem; Merck KGaA and were dissolved in dimethyl sulfoxide (Sigma-Aldrich; Merck KGaA). Based on a previous experiment (28), HPF cells were pretreated with $10 \mu \mathrm{M}$ of each MAPK inhibitor for $1 \mathrm{~h}$ prior to PG treatment at $37^{\circ} \mathrm{C}$.

Cell viability inhibition assays. Briefly, $5 \times 10^{3}$ HPF cells per well in 96-well microtiter plates (Nalge Nunc International; Thermo Fisher Scientific, Inc., Penfield, NY, USA) were exposed to 0,50 or $100 \mu \mathrm{M}$ PG with or without each MAPK inhibitor at $37^{\circ} \mathrm{C}$ for $24 \mathrm{~h}$. Changes in cell viability induced by PG and/or a given MAPK inhibitor were determined by measuring the 3-(4,5-dimethylthiazol-2-yl)-2,5-diphenyltetrazolium bromide (MTT; Sigma-Aldrich; Merck KGaA) dye absorbance as previously described (28).

Lactate dehydrogenase ( $L D H)$ assays. Necrosis in cells was evaluated using an LDH assay kit (Daeil Lab Service Co., Ltd., Seoul, Korea) according to the manufacturer's protocol. Briefly, $1 \times 10^{6} \mathrm{HPF}$ cells in $60 \mathrm{~mm}$ culture plates (Nalge Nunc International; Thermo Fisher Scientific, Inc.) were incubated with 0,50 or $100 \mu \mathrm{M}$ PG in the presence or absence of each MAPK inhibitor at $37^{\circ} \mathrm{C}$ for $24 \mathrm{~h}$. $\mathrm{LDH}$ release was expressed as the percentage of extracellular LDH activity compared with the control cells.

Annexin V/propidium iodide (PI) staining for cell death detection. Apoptosis was determined by staining HPF cells with Annexin V-fluorescein isothiocyanate (FITC; $\mathrm{Ex} / \mathrm{Em}=488 / 519 \mathrm{~nm}$; Invitrogen; Thermo Fisher Scientific, Inc.) and PI $(E x / E m=488 / 617 \mathrm{~nm}$; Sigma-Aldrich; Merck $\mathrm{KGaA}$ ) as previously described (29). Briefly, $1 \times 10^{6} \mathrm{HPF}$ cells in $60 \mathrm{~mm}$ culture plates (Nalge Nunc International; Thermo Fisher Scientific, Inc.) were incubated with 0,50 or $100 \mu \mathrm{M}$ PG in the presence or absence of each MAPK inhibitor at $37^{\circ} \mathrm{C}$ for $24 \mathrm{~h}$. Annexin V/PI staining was analyzed using a FACStar flow cytometer (BD Biosciences, Franklin Lakes, NJ, USA) and CellQuest Pro software (version 5.1; BD Biosciences).

Measurement of mitochondrial membrane potential $\left(M M P ; \Delta \Psi_{m}\right)$. MMP $\left(\Delta \Psi_{\mathrm{m}}\right)$ levels were measured using a rhodamine 123 fluorescent dye (Sigma-Aldrich; Merck KGaA; $\mathrm{Ex} / \mathrm{Em}=485 / 535 \mathrm{~nm})$ as previously described $(28,30,31)$. Briefly, $1 \times 10^{6} \mathrm{HPF}$ cells in $60 \mathrm{~mm}$ culture plates (Nalge Nunc International; Thermo Fisher Scientific, Inc.) were incubated with 0,50 or $100 \mu \mathrm{M}$ PG in the presence or absence of each MAPK inhibitor at $37^{\circ} \mathrm{C}$ for $24 \mathrm{~h}$. Rhodamine 123 staining intensity was determined using a FACStar flow cytometer (BD Biosciences) and CellQuest Pro software (version 5.1; BD Biosciences). The absence of rhodamine 123 from cells indicated the loss of MMP $\left(\Delta \Psi_{\mathrm{m}}\right)$ in HPF cells.

Western blot analysis. Changes in apoptosis and antioxidant system-associated protein levels were determined using western blotting, as previously described (32). Briefly, $1 \times 10^{6} \mathrm{HPF}$ cells in $60 \mathrm{~mm}$ culture plates (Nalge Nunc International; Thermo Fisher Scientific, Inc.) were incubated with 0,50 or $100 \mu \mathrm{M}$ PG in the presence or absence of each MAPK inhibitor at $37^{\circ} \mathrm{C}$ for $24 \mathrm{~h}$. The cells were washed in PBS and suspended in $\sim 100 \mu \mathrm{l}$ of lysis buffer [20 mM HEPES, pH 7.9, $20 \%$ glycerol, $200 \mathrm{mM} \mathrm{KCl}, 0.5 \mathrm{mM}$ EDTA, $0.5 \%$ NP40, $0.5 \mathrm{mM}$ DTT, $1 \%$ protease inhibitor cocktail (Sigma-Aldrich; Merck $\mathrm{KGaA})]$, then centrifuged at $15,900 \mathrm{x}$ g at $4^{\circ} \mathrm{C}$ for $20 \mathrm{~min}$. Samples containing $30 \mu \mathrm{g}$ total protein were resolved by $12.5 \%$ SDS-PAGE, transferred to Immobilon-P polyvinylidene fluoride membranes (Sigma-Aldrich; Merck KGaA) by electroblotting, and the membranes were then probed with anti-poly(ADP-ribose) polymerase (PARP; catalog no., 9542; Cell Signaling Technology, Inc., Danvers, MA, USA; dilution, 1:5,000) and anti-GAPDH antibodies (catalog no., sc-25778; Santa Cruz Biotechnology, Inc., Dallas, TX, USA; dilution, $1: 5,000)$ at $4^{\circ} \mathrm{C}$ overnight without blocking. Next, the membranes were washed with TBS with Tween- 20 four times and incubated with secondary antibody (anti-rabbit IgG; horseradish peroxidase-linked antibody; catalog no., 7074; Cell signaling Technology, Inc.; dilution, 1:5,000) at room temperature for $1 \mathrm{~h}$.

Detection of intracellular $\mathrm{ROS}$ and $\mathrm{O}_{2}^{*-}$ levels. Intracellular ROS were detected using a fluorescent probe dye, $2^{\prime}, 7^{\prime}$-dichlorodihydrofluorescein diacetate $\left(\mathrm{H}_{2} \mathrm{DCFDA}\right.$; $\mathrm{Ex} / \mathrm{Em}=495 / 529 \mathrm{~nm}$; Invitrogen; Thermo Fisher Scientific, Inc.), as previously described (32). Dihydroethidium (DHE; Ex/Em=518/605 nm; Invitrogen; Thermo Fisher Scientific, Inc.) is a fluorogenic probe that is highly selective for $\mathrm{O}_{2}{ }^{-}$among ROS. Mitochondrial $\mathrm{O}_{2}{ }^{-}$levels were detected using a MitoSOX Red mitochondrial $\mathrm{O}_{2}{ }^{*-}$ indicator 
$(E x / E m=510 / 580 \mathrm{~nm}$; Invitrogen; Thermo Fisher Scientific, Inc.) as previously described $(30,31,33)$. Briefly, $1 \times 10^{6} \mathrm{HPF}$ cells in $60 \mathrm{~mm}$ culture plates (Nalge Nunc International; Thermo Fisher Scientific, Inc.) were incubated with 0,50 or $100 \mu \mathrm{M}$ PG in the presence or absence of each MAPK inhibitor for $24 \mathrm{~h}$. DCF, DHE and MitoSOX Red fluorescence was detected using a FACStar flow cytometer (BD Biosciences) and CellQuest Pro software (version 5.1; BD Biosciences). ROS and $\mathrm{O}_{2}^{-{ }^{-}}$levels were expressed as mean fluorescence intensity.

Detection of intracellular GSH. Cellular GSH levels were analyzed using a 5-chloromethylfluorescein diacetate dye (CMF; Ex/Em=522/595 nm; Invitrogen; Thermo Fisher Scientific, Inc.) as previously described $(28,30,31)$. Briefly, $1 \times 10^{6} \mathrm{HPF}$ cells in $60 \mathrm{~mm}$ culture plates (Nalge Nunc International; Thermo Fisher Scientific, Inc.) were incubated with 0,50 or $100 \mu \mathrm{M}$ PG in the presence or absence of each MAPK inhibitor at $37^{\circ} \mathrm{C}$ for $24 \mathrm{~h}$. CMF fluorescence intensity was determined using a FACStar flow cytometer (BD Biosciences) and CellQuest Pro software (version 5.1; BD Biosciences). Negative CMF-staining (GSH-depleted) cells were expressed as a percentage of (-) CMF cells of total cells.

Statistical analysis. The results represent the mean \pm standard deviation of at least three independent experiments. The data were analyzed using Instat software (GraphPad Prism5; GraphPad Software, Inc., La Jolla, CA, USA). Parametric data was analyzed using the Student's t-test (paired) or one-way analysis of variance following by post hoc analysis with Tukey's multiple comparison test. $\mathrm{P}<0.05$ was considered to indicate a statistically significant difference.

\section{Results}

Effects of MAPK inhibitors on cell viability and necrotic cell death in PG-treated HPF cells. The effect of PG on HPF cell viability and necrotic cell death was examined. For these experiments, 0,50 or $100 \mu \mathrm{M}$ PG was used to differentiate the levels of cell viability inhibition or death with or without a given MAPK inhibitor. Treatment with 50 and $100 \mu \mathrm{M}$ PG decreased HPF viability by $\sim 40$ and $65 \%$ at $24 \mathrm{~h}$, respectively (Fig. 1A). Treatment with an MEK inhibitor slightly enhanced the inhibition of cell viability in $50 \mu \mathrm{M}$ PG-treated HPF cells, whereas treatment with a p38 inhibitor mildly attenuated the inhibition of viability (Fig. 1A). In $100 \mu \mathrm{M}$ PG-treated HPF cells, all the MAPK inhibitors increased the inhibition of viability to a certain extent (Fig. 1A), with treatment with the p38 inhibitor alone augmenting HPF control cell viability (Fig. 1A). Necrotic cell death was determined by measuring LDH release from cells. While treatment with $50 \mu \mathrm{M}$ PG did not affect LDH release from HPF cells, $100 \mu \mathrm{M}$ PG significantly increased LDH release (Fig. 1B). Treatment with MAPK inhibitors did not alter LDH activity in PG-treated and untreated HPF cells (Fig. 1B).

Effects of MAPK inhibition on necrotic and apoptotic cell death in PG-treated HPF cells. The tested doses of PG significantly increased the rate of apoptosis in HPF cells, as evidenced by Annexin V-FITC/PI staining (Fig. 2). In addition, treatment
A

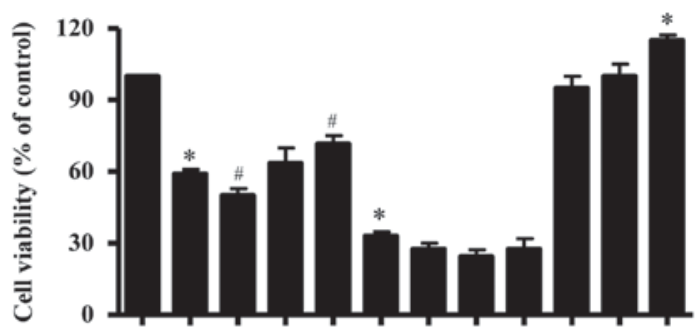

Pyrogallol $\mu \mathrm{M}$ : $\quad-\begin{array}{cccccccccc}50 & 50 & 50 & 50 & 100 & 100 & 100 & 100 & - & -\end{array}$

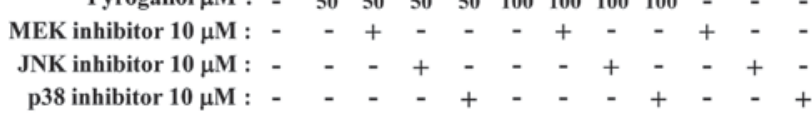

B

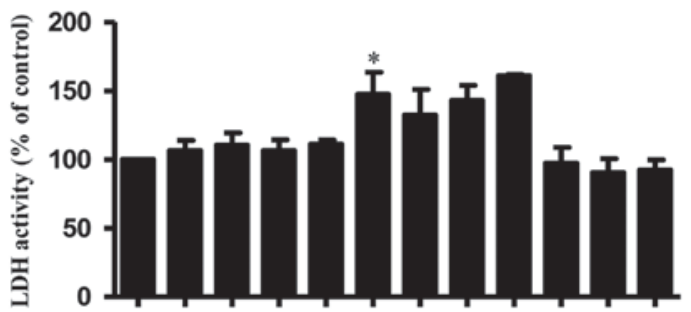

Pyrogallol $\mu \mathrm{M}$ : - $\quad \begin{array}{cccccccccc}50 & 50 & 50 & 50 & 100 & 100 & 100 & 100 & - & -\end{array}$ MEK inhibitor $10 \mu \mathrm{M}:--\quad+-\quad-\quad+--+-$ JNK inhibitor $10 \mu \mathrm{M}:-\quad-\quad-\quad+\quad-\quad-++-$ p38 inhibitor $10 \mu \mathrm{M}:-\quad-\quad-\quad+\quad-\quad-\quad+-\quad+$

Figure 1. Effects of mitogen-activated protein kinase inhibitors on cell viability and necrotic cell death in PG-treated HPF cells. (A) Alterations in HPF cell viability were assessed using MTT assays.(B) Alterations in LDH release from the HPF cells. ${ }^{*} \mathrm{P}<0.05$ vs. control group. ${ }^{\#} \mathrm{P}<0.05$ vs. cells treated with $50 \mu \mathrm{M}$ PG. PG, pyrogallol; HPF, human pulmonary fibroblast; $\mathrm{LDH}$, lactate dehydrogenase; MEK, mitogen-activated protein kinase kinase; JNK, c-Jun N-terminal kinase.

with $100 \mu \mathrm{M}$ PG increased the number of necrotic (Annexin V and $\mathrm{PI}^{+}$) cell death in HPF cells compared with PG-untreated control cells (Fig. 2A). Treatment with the p38 inhibitor slightly increased the number of Annexin $\mathrm{V}^{+} 50 \mu \mathrm{M}$ PG-treated HPF cells compared with only $50 \mu \mathrm{M}$ PG-treated HPF cells, and significantly increased the number of Annexin $\mathrm{V}^{+} 100 \mu \mathrm{M}$ PG-treated cells compared with only $100 \mu \mathrm{M}$ PG-treated HPF cells (Fig. 2A and C). Treatment with the other MAPK inhibitors slightly augmented the number of Annexin $\mathrm{V}^{+} 100 \mu \mathrm{M}$ PG-treated HPF cells compared with only $100 \mu \mathrm{M}$ PG-treated HPF cells (Fig. 2A and C). PARP protein levels were not altered in $50 \mu \mathrm{M}$ PG-treated HPF cells, while it was decreased in $100 \mu \mathrm{M}$ PG-treated cells (Fig. 2C). MEK and p38 inhibitors slightly attenuated the decrease in PARP protein levels in 100 $\mu \mathrm{M}$ PG-treated HPF cells (Fig. 2C). Apoptotic cell death is associated with a decrease in MMP $\left(\Delta \Psi_{\mathrm{m}}\right)$. Treatment with 50 and $100 \mu \mathrm{M}$ PG significantly decreased $\mathrm{MMP}\left(\Delta \Psi_{\mathrm{m}}\right)$ in HPF cells (Fig. 2B and D). All the MAPK inhibitors enhanced the decrease in MMP $\left(\Delta \Psi_{\mathrm{m}}\right)$ in PG-treated HPF cells, and treatment with the JNK inhibitor demonstrated a significant effect on $100 \mu \mathrm{M}$ PG-treated HPF cells (Fig. 2B and D).

Effects of MAPK inhibitors on ROS levels in PG-treated HPF cells. To assess the level of intracellular ROS in HPF 
A
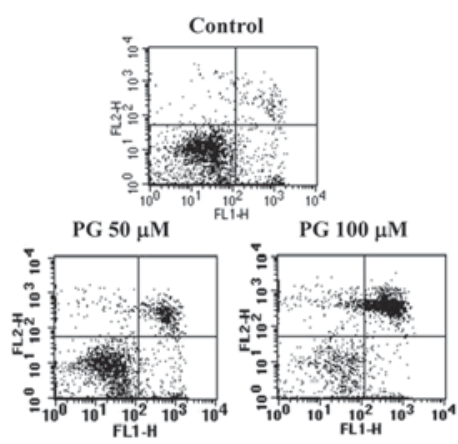

PG $50 \mu \mathrm{M}+$ MEK I. PG $100 \mu \mathrm{M}+$ MEK I.
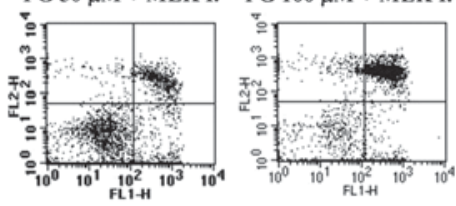

PG $50 \mu \mathrm{M}+$ JNK I.

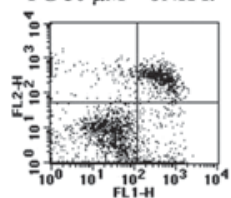

PG $100 \mu \mathrm{M}+$ JNK I.
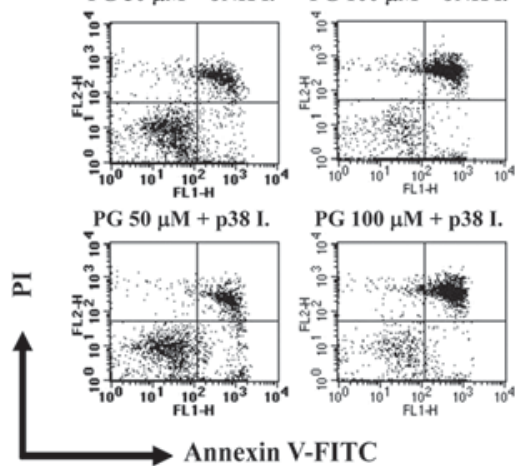

B

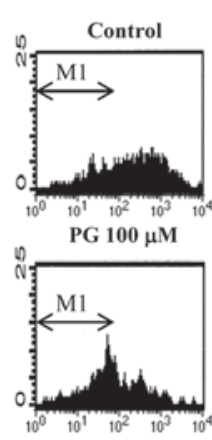

PG $100 \mu \mathrm{M}+$ MEK I.
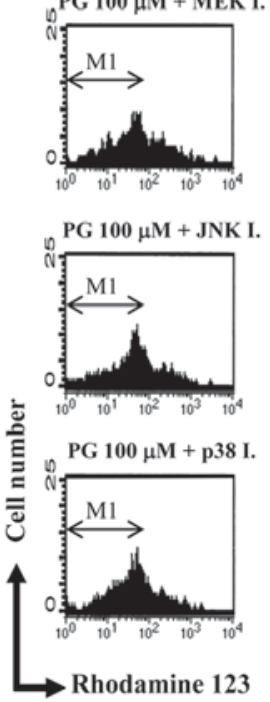

C
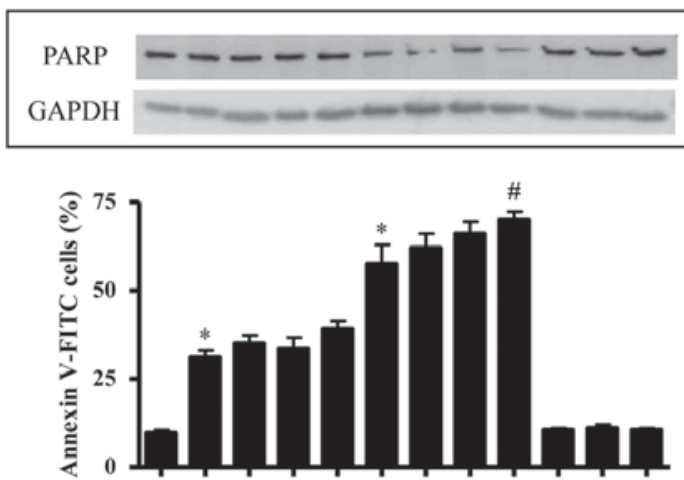

D

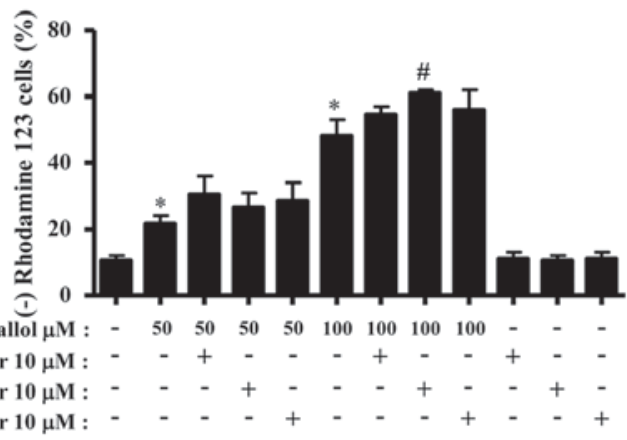

Figure 2. Effects of mitogen-activated protein kinase inhibitors on apoptosis and MMP $\left(\Delta \Psi_{\mathrm{m}}\right)$ in PG-treated HPF cells. (A) Representative graphs depicting the results of Annexin V-FITC/PI staining. (B) Representative graphs depicting the results of rhodamine 123 staining. M1 regions indicate rhodamine $123-$ cells, with decreased MMP $\left(\Delta \Psi_{\mathrm{m}}\right)$. (C) PARP and GAPDH protein levels were assessed in PG-treated HPF cells by western blot. The graph depicts the percentage of Annexin $\mathrm{V}^{+}$cells from A. (D) The percentage of rhodamine $123^{-}$cells from $\mathrm{B} .{ }^{*} \mathrm{P}<0.05$ vs. control group. ${ }^{\#} \mathrm{P}<0.05$ vs. cells treated with $100 \mu \mathrm{M}$ PG. MMP $\left(\Delta \Psi_{\mathrm{m}}\right)$, mitochondrial membrane potential; PG, pyrogallol; HPF, human pulmonary fibroblast; FITC, fluorescein isothiocyanate; PI, propidium iodide; PARP, poly(ADP-ribose) polymerase; MEK, mitogen-activated protein kinase kinase; JNK, c-Jun N-terminal kinase.

cells treated with PG, DHE, $\mathrm{H}_{2}$ DCFDA and MitoSOX Red fluorescent dyes were used (Fig. 3). The level of DHE fluorescent dye, which reflects the accumulation of $\mathrm{O}_{2}{ }^{-}$in cells, increased in HPF cells treated with PG (Fig. 3A and D). All the MAPK inhibitors were likely to increase $\mathrm{O}_{2}{ }^{-}$level in $100 \mu$ M PG-treated HPF cells (Fig. 3A and D). ROS (DCF) level in HPF cells was increased by $50 \mu \mathrm{M}$ PG treatment but not $100 \mu \mathrm{M}$ PG treatment (Fig. 3C). All the MAPK inhibitors decreased ROS levels in HPF cells treated with $50 \mu \mathrm{M}$ PG, and treatment with p38 and JNK inhibitors also decreased the level of ROS in $100 \mu \mathrm{M}$ PG-treated HPF cells (Fig. 3C). Furthermore, MitoSOX Red fluorescence levels, indicating the presence of mitochondrial $\mathrm{O}_{2}{ }^{-}$, were markedly increased in PG-treated HPF cells (Fig. 3B and E). Treatment with a p38 inhibitor increased mitochondrial $\mathrm{O}_{2}^{-{ }^{-}}$levels in PG-treated HPF cells, whereas treatment with an MEK inhibitor slightly decreased mitochondrial $\mathrm{O}_{2}^{-{ }^{-}}$levels (Fig. 3B and E). Treatment with a JNK inhibitor reduced the mitochondrial $\mathrm{O}_{2}{ }^{--}$level in HPF control cells (Fig. 3E).

Effects of MAPK inhibitors on GSH levels in PG-treated HPF cells. Changes in intracellular GSH levels in HPF cells treated with PG and/or each MAPK inhibitor were assessed using a CMFDA dye. Treatment with 50 or $100 \mu \mathrm{M}$ PG significantly increased the number of GSH-depleted cells in HPF cells compared with the negative control (Fig. 4). None of the MAPK inhibitors significantly altered GSH depletion in PG-treated or untreated HPF cells (Fig. 4).

\section{Discussion}

PG is known to trigger the collapse of MMP $\left(\Delta \Psi_{\mathrm{m}}\right)$ and $\mathrm{O}_{2}{ }^{-}$-mediated cell death via apoptosis in various types of cancer cell $(7,8,24,25,34)$. In the present study, PG increased $\mathrm{O}_{2}{ }^{-*}$ levels, particularly mitochondrial $\mathrm{O}_{2}{ }^{-*}$ levels, in HPF cells and induced decreased MMP $\left(\Delta \Psi_{\mathrm{m}}\right)$. The high production of mitochondrial $\mathrm{O}_{2}^{-}$in PG-treated HPF cells resulted in cell death. In particular, treatment with $100 \mu \mathrm{M}$ PG induced apoptosis as well as necrosis in HPF cells.

In general, the activation of ERK is pro-survival rather than pro-apoptotic (18). The results of the present study demonstrated that treatment with an MEK inhibitor, which resulted in decreased ERK activity, enhanced the inhibition of cell viability, cell death and MMP $\left(\Delta \Psi_{\mathrm{m}}\right)$ loss in PG-treated HPF cells, suggesting that ERK signaling in PG-treated HPF cells is involved in HPF cell survival. In addition, treatment with an 
A

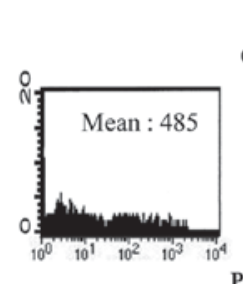

B

Control

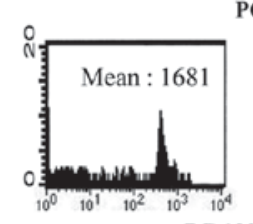

PG $100 \mu \mathrm{M}$
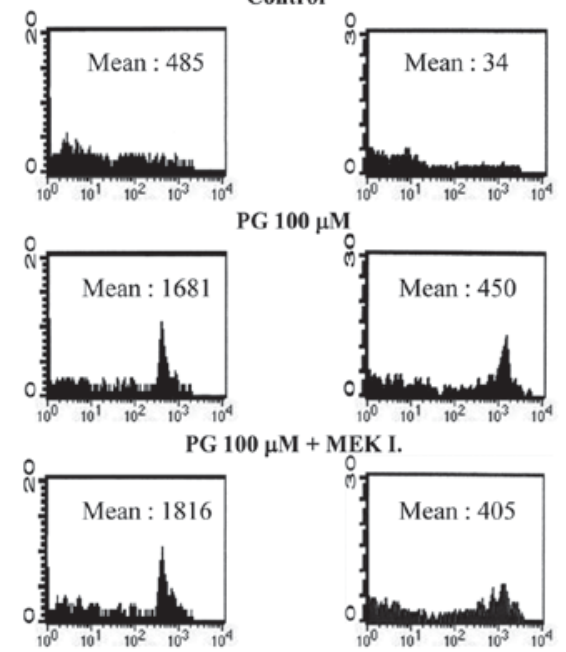

MEK I.

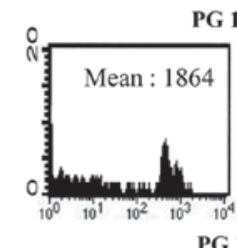

PG $100 \mu \mathrm{M}+$ JNK I.

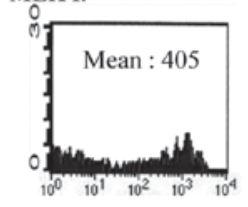

$\mathbf{E}$

C
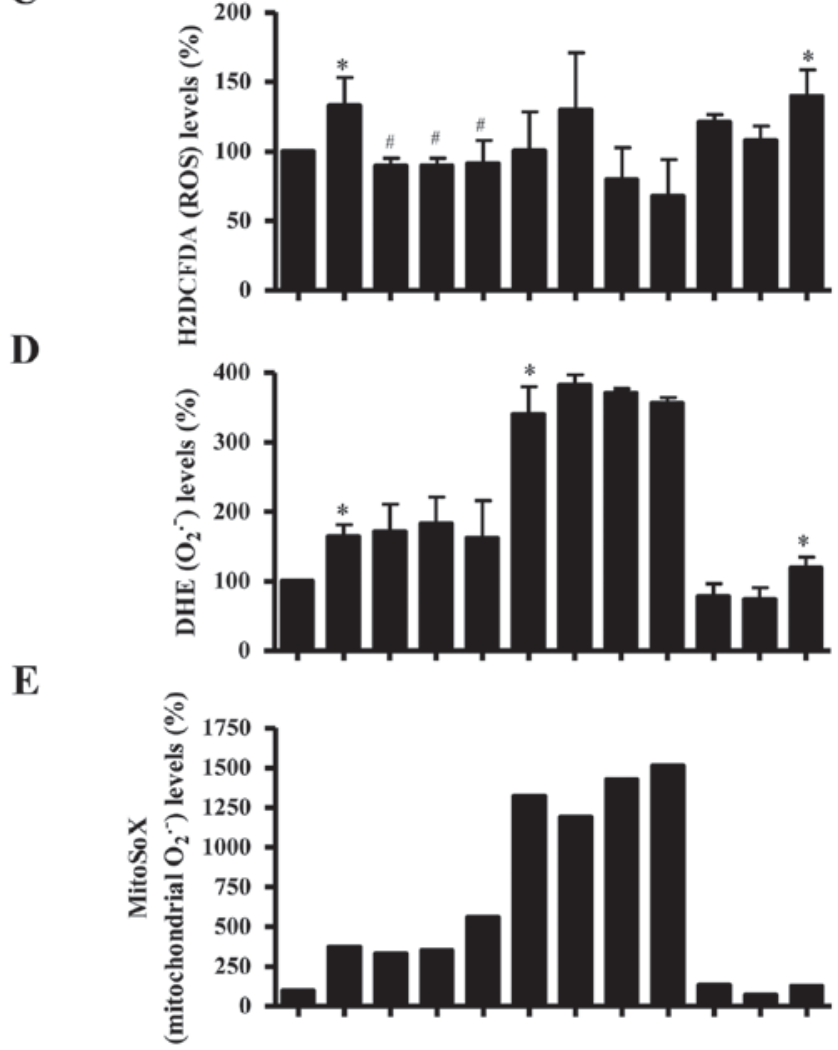

Pyrogallol $\mu \mathrm{M}:-\begin{array}{ccccccccccc}50 & 50 & 50 & 50 & 100 & 100 & 100 & 100 & - & - & -\end{array}$

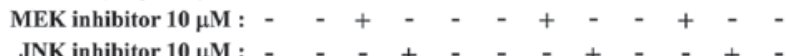

p38 inhibitor $10 \mu \mathrm{M}$ : - $-\quad-\quad+\quad-\quad-\quad+-\quad-+$

Figure 3. Effects of mitogen-activated protein kinase inhibitors on ROS levels in PG-treated HPF cells. ROS levels were measured using a FACStar flow cytometer. Representative graphs of (A) DHE $\left(\mathrm{O}_{2}^{*}\right)$ and (B) mitoSOX (mitochondrial $\mathrm{O}_{2}^{\circ}$ ) levels in PG-treated HPF cells. (C) The graph indicates the percentage of ROS (as determined by $\mathrm{H}_{2}$ DCFDA) levels compared with the control cells. The graphs indicate the percentage of (D) DHE ( $\left.\mathrm{O}_{2}{ }^{\circ}\right)$ levels from (A and $\mathrm{E}$ ) mitoSOX (mitochondrial $\mathrm{O}_{2}^{\circ}$ ) levels from (B) compared with the control cells. ${ }^{*} \mathrm{P}<0.05$ vs. control group. ${ }^{*} \mathrm{P}<0.05$ vs. cells treated with $50 \mu \mathrm{M}$ PG. ROS, reactive oxygen species; PG, pyrogallol; HPF, human pulmonary fibroblast; DHE, dihydroethidium; $\mathrm{H}_{2} \mathrm{DCFDA}, 2^{\prime}$ '7'-dichlorodihydrofluorescein diacetate; MEK, mitogen-activated protein kinase kinase; JNK, c-Jun N-terminal kinase.

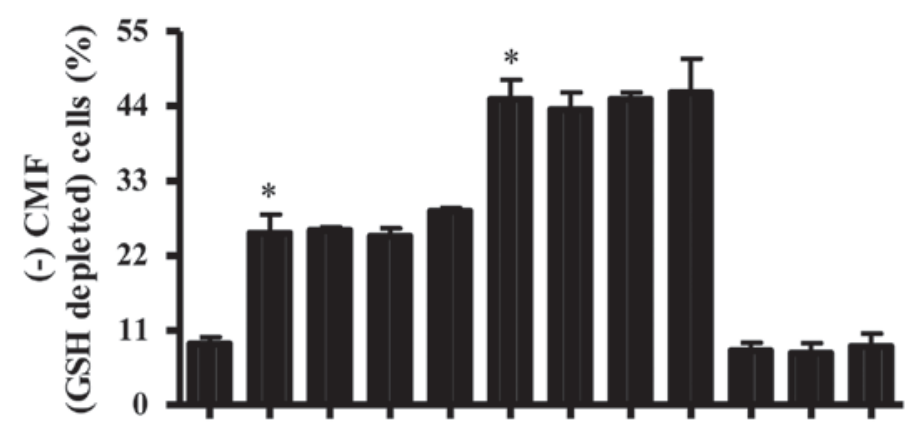

Pyrogallol $\mu \mathrm{M}:-\begin{array}{ccccccccccc} & 50 & 50 & 50 & 50 & 100 & 100 & 100 & 100 & - & -\end{array}$

MEK inhibitor $10 \mu \mathrm{M}:-\quad-\quad+\quad-\quad-\quad+-\frac{-}{-}-\quad-$

JNK inhibitor $10 \mu \mathrm{M}:-\quad-\quad-\quad+\quad-\quad-\quad+\quad-\quad-\quad+\quad-$

p38 inhibitor $10 \mu \mathrm{M}$ : - $-\quad-\quad-\quad+\quad-\quad-\quad+\quad-\quad-\quad+$

Figure 4. Effects of mitogen-activated protein kinase inhibitors on GSH levels in PG-treated HPF cells. GSH levels were measured with a FACStar flow cytometer. The graph depicts the percentage of $\mathrm{CMF}^{-}$(GSH-depleted) cells. "P<0.05 vs. control group. GSH, glutathione; PG, pyrogallol; HPF, human pulmonary fibroblast; CMF, chloromethylfluorescein diacetate; MEK, mitogen-activated protein kinase kinase; JNK, c-Jun N-terminal kinase.

MEK inhibitor increased ROS levels in $100 \mu \mathrm{M}$ PG-treated HPF cells. However, this inhibitor decreased ROS levels in $50 \mu \mathrm{M}$ PG-treated HPF cells and decreased the mitochondrial
$\mathrm{O}_{2}{ }^{-}$level in PG-treated 50 and $100 \mu \mathrm{M}$ HPF cells. These results suggested that the different effects of MEK inhibition on ROS levels in HPF cells are dependent on the incubation doses of PG. 
The JNK and p38 signaling pathways have been suggested to be associated with cell death $(14,19,35)$. Previous data have also demonstrated that JNK and p38 inhibitors significantly prevent the inhibition of cell growth, cell death and MMP $\left(\Delta \Psi_{\mathrm{m}}\right)$ loss in PG-treated As4.1 juxtaglomerular cells (36). In contrast, treatment with a JNK inhibitor enhanced the inhibition of cell growth, cell death and MMP $\left(\Delta \Psi_{\mathrm{m}}\right)$ loss in PG-treated calf pulmonary arterial endothelial cells, whereas treatment with a p38 inhibitor significantly attenuated these effects in the same cells (28). According to the results of the present study, treatment with JNK and p38 inhibitors increased the inhibition of HPF cell viability, cell death and MMP $\left(\Delta \Psi_{\mathrm{m}}\right)$ loss following treatment with $100 \mu \mathrm{M}$ PG, implying that the JNK and p38 signaling pathways in PG-treated HPF cells are pro-survival rather than pro-apoptotic. In addition, treatment with JNK and p38 inhibitors slightly increased $\mathrm{O}_{2}{ }^{--}$levels in $100 \mu \mathrm{M}$ PG-treated HPF cells, whereas these same inhibitors decreased ROS (DCF) levels in 50 and $100 \mu \mathrm{M}$ PG-treated HPF cells. These results suggested that it was the JNK or p38 MEK inhibitor-induced altered $\mathrm{O}_{2}{ }^{--}$levels rather than ROS (DCF) levels that influenced PG-induced cell death. Furthermore, treatment with a p38 inhibitor partially attenuated the inhibition of $50 \mu \mathrm{M}$ PG-treated HPF cell viability, and this inhibitor alone significantly increased cell viability and ROS levels, including $\mathrm{O}_{2}{ }^{--}$, in HPF control cells without the induction of cell death. Treatment with a JNK inhibitor alone also specifically affected mitochondrial $\mathrm{O}_{2}{ }^{-*}$ levels independent to HPF cell viability and death. These results indicated that JNK and p38 inhibition differently influences ROS levels, cell viability and cell death in HPF cells, which are altered depending on the concentration of PG.

PG induces GSH depletion in a variety of cells $(9,26,28,37)$. The results of the present study also demonstrated that PG treatment increased the number of GSH-depleted HPF cells in a dose-dependent manner. However, none of the MAPK inhibitors, which demonstrated a partial effect on HPF cell death, altered the number of GSH-depleted cells following treatment with 50 and $100 \mu \mathrm{M}$ PG. Therefore, the intracellular GSH content was at least partially associated with PG-induced HPF cell death.

In conclusion, PG induced apoptosis as well as necrosis in HPF cells. MAPK inhibitors slightly promoted cell death in PG-treated HPF cells. HPF cell death following treatment with PG and/or MAPK inhibitors was partially associated with the $\mathrm{O}_{2}{ }^{--}$level and changes in GSH content. The results of the present study enhance understanding of PG-induced cell death on normal lung cells in association with MAPK signaling pathways and ROS levels.

\section{Acknowledgements}

The present study was supported by a grant from the National Research Foundation of Korea, funded by the Korean government (Ministry of Science, ICT and Future Planning; grant nos., 20080062279 and 2016R1A2B4007773).

\section{References}

1. Upadhyay G, Gupta SP, Prakash O and Singh MP: Pyrogallol-mediated toxicity and natural antioxidants: Triumphs and pitfalls of preclinical findings and their translational limitations. Chem Biol Interact 183: 333-340, 2010.
2. Upadhyay G, Tiwari MN, Prakash O, Jyoti A, Shanker R and Singh MP: Involvement of multiple molecular events in pyrogallol-induced hepatotoxicity and silymarin-mediated protection: Evidence from gene expression profiles. Food Chem Toxicol 48: 1660-1670, 2010.

3. Gupta YK, Sharma M and Chaudhary G: Pyrogallol-induced hepatotoxicity in rats: A model to evaluate antioxidant hepatoprotective agents. Methods Find Exp Clin Pharmacol 24: 497-500, 2002.

4. Sharma M, Rai K, Sharma SS and Gupta YK: Effect of antioxidants on pyrogallol-induced delay in gastric emptying in rats. Pharmacology 60: 90-96, 2000.

5. Saeki K, Hayakawa S, Isemura M and Miyase T: Importance of a pyrogallol-type structure in catechin compounds for apoptosis-inducing activity. Phytochemistry 53: 391-394, 2000.

6. Sawada M, Nakashima S, Kiyono T, Nakagawa M, Yamada J, Yamakawa H, Banno Y, Shinoda J, Nishimura Y, Nozawa Y and Sakai N: p53 regulates ceramide formation by neutral sphingomyelinase through reactive oxygen species in human glioma cells. Oncogene 20: 1368-1378, 2001.

7. Park WH, Park MN, Han YH and Kim SW: Pyrogallol inhibits the growth of gastric cancer SNU-484 cells via induction of apoptosis. Int J Mol Med 22: 263-268, 2008.

8. Han YH, Kim SZ, Kim SH and Park WH: Pyrogallol inhibits the growth of lung cancer Calu-6 cells via caspase-dependent apoptosis. Chem Biol Interact 177: 107-114, 2009.

9. Han YH, Kim SZ, Kim SH and Park WH: Apoptosis in pyrogallol-treated Calu- 6 cells is correlated with the changes of intracellular GSH levels rather than ROS levels. Lung Cancer 59: 301-314, 2008

10. Zorov DB, Juhaszova M and Sollott SJ: Mitochondrial ROS-induced ROS release: An update and review. Biochim Biophys Acta 1757: 509-517, 2006

11. Zelko IN, Mariani TJ and Folz RJ: Superoxide dismutase multigene family: A comparison of the CuZn-SOD (SOD1), Mn-SOD (SOD2), and EC-SOD (SOD3) gene structures, evolution, and expression. Free Radic Biol Med 33: 337-349, 2002.

12. Wilcox CS: Reactive oxygen species: Roles in blood pressure and kidney function. Curr Hypertens Rep 4: 160-166, 2002.

13. Guyton KZ, Liu Y, Gorospe M, Xu Q and Holbrook NJ: Activation of mitogen-activated protein kinase by $\mathrm{H} 2 \mathrm{O} 2$. Role in cell survival following oxidant injury. J Biol Chem 271: 4138-4142, 1996.

14. Mao X, Yu CR, Li WH and Li WX: Induction of apoptosis by shikonin through a ROS/JNK-mediated process in Bcr/Abl-positive chronic myelogenous leukemia (CML) cells. Cell Res 18: 879-888, 2008.

15. Gomez-Lazaro M, Galindo MF, Melero-Fernandez de Mera RM, Fernandez-Gómez FJ, Concannon CG, Segura MF, Comella JX, Prehn JH and Jordan J: Reactive oxygen species and p38 mitogen-activated protein kinase activate Bax to induce mitochondrial cytochrome $\mathrm{c}$ release and apoptosis in response to malonate. Mol Pharmacol 71: 736-743, 2007.

16. Blenis J: Signal transduction via the MAP kinases: Proceed at your own RSK. Proc Natl Acad Sci USA 90: 5889-5892, 1993.

17. Kusuhara M, Takahashi E, Peterson TE, Abe J, Ishida M, Han J, Ulevitch R and Berk BC: p38 Kinase is a negative regulator of angiotensin II signal transduction in vascular smooth muscle cells: Effects on $\mathrm{Na}+/ \mathrm{H}+$ exchange and ERK1/2. Circ Res 83: 824-831, 1998.

18. Henson ES and Gibson SB: Surviving cell death through epidermal growth factor (EGF) signal transduction pathways: Implications for cancer therapy. Cell Signal 18: 2089-2097, 2006.

19. Kang YH and Lee SJ: The role of p38 MAPK and JNK in Arsenic trioxide-induced mitochondrial cell death in human cervical cancer cells. J Cell Physiol 217: 23-33, 2008.

20. Hsia CC, Hyde DM and Weibel ER: Lung structure and the intrinsic challenges of gas exchange. Compr Physiol 6: 827-895, 2016.

21. Kalluri R: The biology and function of fibroblasts in cancer. Nat Rev Cancer 16: 582-598, 2016.

22. You BR and Park WH: Arsenic trioxide induces human pulmonary fibroblast cell death via increasing ROS levels and GSH depletion. Oncol Rep 28: 749-757, 2012.

23. You BR and Park WH: Gallic acid-induced human pulmonary fibroblast cell death is accompanied by increases in ROS level and GSH depletion. Drug Chem Toxicol 34: 38-44, 2011.

24. Han YH, Kim SH, Kim SZ and Park WH: Pyrogallol inhibits the growth of human pulmonary adenocarcinoma A549 cells by arresting cell cycle and triggering apoptosis. J Biochem Mol Toxicol 23: 36-42, 2009. 
25. Han YH, Kim SZ, Kim SH and Park WH: Pyrogallol inhibits the growth of human lung cancer Calu- 6 cells via arresting the cell cycle arrest. Toxicol in vitro 22: 1605-1609, 2008.

26. Han YH, Kim SZ, Kim SH and Park WH: Pyrogallol as a glutathione depletor induces apoptosis in HeLa cells. Int J Mo Med 21: 721-730, 2008.

27. Han YH, Moon HJ, You BR and Park WH: The effects of MAPK inhibitors on pyrogallol-treated Calu-6 lung cancer cells in relation to cell growth, reactive oxygen species and glutathione. Food Chem Toxicol 48: 271-276, 2010.

28. Han YH, Moon HJ, You BR, Kim SZ, Kim SH and Park WH: JNK and p38 inhibitors increase and decrease apoptosis, respectively, in pyrogallol-treated calf pulmonary arterial endothelial cells. Int J Mol Med 24: 717-722, 2009.

29. Han YH and Park WH: Propyl gallate inhibits the growth of $\mathrm{HeLa}$ cells via regulating intracellular GSH level. Food Chem Toxicol 47: 2531-2538, 2009.

30. Han YH, Kim SH, Kim SZ and Park WH: Carbonyl cyanide p-(trifluoromethoxy) phenylhydrazone $(\mathrm{FCCP})$ as an $\mathrm{O} 2\left({ }^{*}-\right)$ generator induces apoptosis via the depletion of intracellular GSH contents in Calu-6 cells. Lung Cancer 63: 201-209, 2009.

31. Park WH and You BR: Antimycin A induces death of the human pulmonary fibroblast cells via ROS increase and GSH depletion. Int J Oncol 48: 813-820, 2016.

32. You BR, Shin HR, Han BR and Park WH: PX-12 induces apoptosis in Calu- 6 cells in an oxidative stress-dependent manner. Tumour Biol 36: 2087-2095, 2015.

33. Han YH, Kim SH, Kim SZ and Park WH: Caspase inhibitor decreases apoptosis in pyrogallol-treated lung cancer Calu-6 cells via the prevention of GSH depletion. Int J Oncol 33 1099-1105, 2008.
34. Han YH, Moon HJ, You BR and Park WH: The anti-apoptotic effects of caspase inhibitors on propyl gallate-treated HeLa cells in relation to reactive oxygen species and glutathione levels. Arch Toxicol 83: 825-833, 2009.

35. Hsin YH, Chen CF, Huang S, Shih TS, Lai PS and Chueh PJ The apoptotic effect of nanosilver is mediated by a ROS- and JNK-dependent mechanism involving the mitochondrial pathway in NIH3T3 cells. Toxicol Lett 179: 130-139, 2008.

36. Han YH and Park WH: Pyrogallol-induced As4.1 juxtaglomerular cell death is attenuated by MAPK inhibitors via preventing GSH depletion. Arch Toxicol 84: 631-640, 2010.

37. Park WH, Han YW, Kim SH and Kim SZ: A superoxide anion generator, pyrogallol induces apoptosis in As4.1 cells through the depletion of intracellular GSH content. Mutat Res 619: 81-92, 2007. 